\title{
Fatal pulmonary thromboembolism during total hip replacement under spinal anesthesia
}

\author{
Yong-Hyun Cho, Sun-Hee Kim, Dong-Hyun Lee, Seong-Hyon Jeon, and Seung-Hyun Kang
}

Department of Anesthesiology and Pain Medicine, Seoul Sungsim General Hospital, Seoul, Korea

The development of pulmonary thromboembolism (PTE) in high risk patients during surgery is not uncommon. Although it is difficult to make a prompt diagnosis due to its nonspecific symptoms, it is imperative to make an early diagnosis and provide proper treatment for a good prognosis. In our case, PTE developed in a high risk patient even after preventive measures of venous thromboembolism (VTE) during total hip replacement (THR) under spinal anesthesia.

An 86-year-old male patient, weighing $79 \mathrm{~kg}$, with a height of $165 \mathrm{~cm}$ was admitted for the treatment of subluxation of the right hip for which he had undergone revision THR 5 years ago. He was on hypertensive medication. After reduction and 12 days of absolute bed rest, we decided to carry out re-revision THR of the right hip because the pain did not subside. Considering the patient's old age, the 11 days of immobilization after the reduction, and the several risk factors for VTE (obesity, THR, etc.) that were present, graduated compression stockings were applied 4 days prior to the surgery and $40 \mathrm{mg}$ of enoxaparin was administered 12 hours before the operation. Preoperative laboratory findings and examinations were normal except for mild aortic regurgitation on echocardiography and mild fatty liver on abdominal ultrasonography. Before initiating spinal anesthesia, the initial blood pressure (BP) was $160 / 90 \mathrm{mmHg}$, heart rate $(\mathrm{HR})$ at 70 beats/min, and pulse oxygen saturation $\left(\mathrm{SpO}_{2}\right)$ was $99 \%$ with an $\mathrm{O}_{2} 2 \mathrm{~L} / \mathrm{min}$ via nasal prongs. After achieving adequate spinal anesthesia, major surgical procedures were carried out without significant events and the estimated blood loss was $900 \mathrm{ml}$, and 2 pints of packed red blood cells were transfused. During skin closure, the BP decreased to $60 / 40 \mathrm{mmHg}$ and the
$\mathrm{HR}$ increased to 120 beats/min. The $\mathrm{SpO}_{2}$ abruptly decreased from 99 to $78 \%$. The patient was tachypneic and complained of chest pain. Soon after, his mental status quickly deteriorated. Ten L/min of $100 \%$ oxygen via facial mask was applied and fluid resuscitation was initiated. The patient's position was changed to supine as soon as the skin closure was completed. Meanwhile, ephedrine (total of $25 \mathrm{mg}$ ) and phenylephrine (100 ug) were injected and invasive arterial BP measurement was started through the radial artery. The BP increased to $80 / 50 \mathrm{mmHg}$ and HR was 110 beats/min. Arterial blood gas analysis (ABGA) results were $\mathrm{pH} 7.29, \mathrm{PaCO}_{2} 69.8 \mathrm{mmHg}, \mathrm{PaO}_{2} 61 \mathrm{mmHg}$, and $\mathrm{SaO}_{2} 81 \%$. After intubating the patient, dopamine $(15 \mu \mathrm{g} / \mathrm{kg} /$ $\mathrm{min})$ and epinephrine $(0.1 \mu \mathrm{g} / \mathrm{kg} / \mathrm{min})$ infusions were initiated. $\mathrm{BP}, \mathrm{HR}$, and end-tidal $\mathrm{CO}_{2}\left(\mathrm{ETCO}_{2}\right)$ were checked 15 minutes after intubation and they were 140/90 $\mathrm{mmHg}, 120$ beats/min and $28 \mathrm{mmHg}$, respectively. ABGA results were $\mathrm{pH}$ 7.36, $\mathrm{PaCO}_{2}$ $41 \mathrm{mmHg}, \mathrm{PaO}_{2} 138.6 \mathrm{mmHg}$, and $\mathrm{SaO}_{2}$ 98.2\%. Under suspicion of PTE, trans-esophageal echocardiography (TEE) was carried out and emboli in the right atrium with bulging of the right atrial wall intothe left atrium were noted. After transferring the patient to the intensive care unit (ICU), the ventilator was set to the following: $\mathrm{FiO}_{2}$ 1.0, synchronized intermittent mandatory ventilation mode 12 breaths/min, and tidal volume $600 \mathrm{ml}$. ABGA done at the ICU did not improve; $\mathrm{pH}$ was 7.26, $\mathrm{PaCO}_{2} 58$ $\mathrm{mmHg}, \mathrm{PaO}_{2} 68 \mathrm{mmHg}$, and $\mathrm{SaO}_{2} 86.2 \%$. Thus, heparin therapy was initiated 2 hours after the operation (5000 IU bolus injection followed by $800 \mathrm{IU} / \mathrm{hr}$ to maintain $1.5-2$ times the normal activated partial thromboplastin time level). This resulted in an improvement of the ABGA results: $\mathrm{pH}$ was $7.37, \mathrm{PaCO}_{2} 46$

Corresponding author: Yong-Hyun Cho, M.D., Department of Anesthesiology and Pain Medicine, Seoul Sungsim General Hospital, 40-12, Cheongnyangni-dong, Dongdaemun-gu, Seoul 130-866, Korea. Tel: 82-2-966-1616, Fax: 82-2-968-2394, E-mail: anesthecho@naver.com (c) This is an open-access article distributed under the terms of the Creative Commons Attribution Non-Commercial License (http:// creativecommons.org/licenses/by-nc/3.0/), which permits unrestricted non-commercial use, distribution, and reproduction in any medium, provided the original work is properly cited. 
mmHg, $\mathrm{PaO}_{2} 110 \mathrm{mmHg}$, and $\mathrm{SaO}_{2}$ 97\%. 5 days later, the endotracheal tube was removed and $5 \mathrm{~L} / \mathrm{min}$ oxygen via a face mask was initiated. Fourteen days later, no thrombosis was found on spiral computer tomography (CT) and the heparin infusion was stopped. Seventeen days later, the patient's vital signs were stable and thus, he was transferred to the general ward.

PTE is a relatively common cardiovascular emergency. VTE is a broad concept which includes PTE and deep vein thrombosis (DVT). One investigation done in the US claims that 5 million cases of DVT develop every year and $10 \%$ of these cases causes PTE and $10 \%$ of the patients die from it [1]. VTE prevention can be divided into non-pharmacologic (stockings and pneumatic compression devices) and pharmacologic treatment (low-dose subcutaneous unfractionated heparin,low molecular weight heparin, and fondaparinux). Clinical findings of PTE include dyspnea, chest pain, cough, syncope, hemoptysis, high fever, tachycardia, hypotension, and tachypnea. ABGA results may show respiratory alkalosis, hypoxemia, increased arterial to $\mathrm{ETCO}_{2}$ gradient, etc. Righini et al. [2] reported that only $20 \%$ of clinically suspected patients are finally diagnosed as having PTE. When PTE is clinically suspected and the patient is hemodynamically stable, with anincreased D-dimer, the diagnosis can be made through multidetector CT scanning or ventilationperfusion scanning. If the patient is hemodynamically unstable, immediate multidetector CT scanning is performed for the PTE diagnosis. Multidetector CT has $97 \%$ sensitivity in finding main pulmonary artery emboli [3]. As in our case, if the CT is not a viable option due to the patient's condition, bedside TEE can be used to make the diagnosis. Pruszczyk et al. [4] reported that diagnosing PTE with TEE compared to diagnosis with angiography results in $100 \%$ sensitivity and $80 \%$ specificity, and compared to CT, results in $90 \%$ sensitivity and $100 \%$ specificity. If a patient is hemodynamically unstable and has clinical and laboratory findings that are suspicious for PTE, appropriate and timely management must be performed even if emboli are not found and only indirect signs such as wall dysfunction, tricuspid valve regurgitation, and right to left interseptal bowing are noted. When PTE develops, it causes acute RV failure which may result in death due to systemic output loss. Thus, hemodynamic and respiratory support in a PTE patient is very important. The mainstay of PTE treatment includes anticoagulation, pharmacological thrombolysis, and mechanical thrombolysis. In hemodynamically unstable patients, aggressive treatment such as pharmacologic or mechanical thrombolysis must be performed. Intracranial disease, uncontrolled hypertension, recent major surgery (within 3 weeks) and trauma are contraindications of thrombolytic therapy. Since the early diagnosis and treatment of PTE is essential for a good prognosis, we must always take into consideration the possibility of PTE when non-specific clinical symptoms (dyspnea, hypotension, chest pain, etc) develop, and adequate diagnostic tools must be utilized, followed by proper and prompt management.

\section{References}

1. White RH. The epidemiology of venous thromboembolism. Circulation 2003; 107(23 Suppl 1): I4-8.

2. Righini M, Le Gal G, Aujesky D, Roy PM, Sanchez O, Verschuren F, et al. Diagnosis of pulmonary embolism by multidetector CT alone or combined with venous ultrasonography of the leg: a randomised non-inferiority trial. Lancet 2008; 371: 1343-52.

3. van Belle A, Büller HR, Huisman MV, Huisman PM, Kaasjager K, Kamphuisen PW, et al. Effectiveness of managing suspected pulmonary embolism using an algorithm combining clinical probability, D-dimer testing, and computed tomography. JAMA 2006; 295 : $172-9$.

4. Pruszczyk P, Torbicki A, Pacho R, Chlebus M, Kuch-Wocial A, Pruszynski B, et al. Noninvasive diagnosis of suspected severe pulmonary embolism: transesophageal echocardiography vs spiral CT. Chest 1997; 112: 722-8. 